\section{O Sistema Único de Saúde e as Populações Indigenas: Por uma Integração Diferenciada}

\author{
Ulisses E. C. Confalonieri *
}

\section{INTRODUÇÃO}

No momento em que se procura consolidar o Sistema Único de Saúde no Paŕs, segundo os princípios e diretrizes estabelecidos na 8: Conferéncia Nacional de Saúde e consagrados na Nova Constituiçáo, mais uma vez se coloca a questão da assistência às populações indígenas no Brasil.

$\mathrm{Na}$ Conferéncia Nacional de Proteçáo à Sáde do f́ndio, realizada em novembro de 1986, tema específico que se seguiu à 8: Conferéncia, aspectos relacionados a políticas de saúde para grupos indígenas foram discutidos e propostas foram encaminhadas. O que se faz necessário agora $E$ a retomada destes temas - reflexōes sobre as conseqüéncias da aplicação das novas orientações do Sistema Unico para as comunidades aborigenes, em funçáo ie sua situaçăo peculiar no conjunto da sociedade brasileira, para que estas possam efetivamente ser contempladas com os beneffcios da seguridade social e da universalizaçäo do atendimento.

Com base nas diretrizes e princípios fundamentais do Sistema Unico, seráo discutidas neste trabalho algumas peculiaridades relativas à assistência à saúde em áreas indígenas, revendo-se sumariamente algumas das experiências brasileiras recentes neste campo. Concluiremos com algumas sugestóes de estratégias a serem implementadas no sentido de se estender, de forma mais eficaz, a participação do Estado nos cuidados de saúde aos grupos tribais do território brasileiro.

\section{O ATENDIMENTO AO INDIO BRASILEIRO}

Sendo o SUS a reafimaçāo da responsabilidade do Estado no financiamento, organizaçáo e gestảo de um sistema abrangente de cuidados à sáde, com cobertura universal a todos os habitantes do territorio, a extensão da rede de serviços aos grupos indígenas ocorre, por princípio, de forma automática. Deve-se, no entanto, avaliar as implicaçóes de tal descentra-

- Coordenador, Centro de Estu dos de Sanide de Populacóes Indt genas - ENSPI FIOCRUZ 
lização, com a execuçăo direta de açōes em áreas cultural e linguiisticamente diferenciadas, freqüentemente isoladas fisicamente, bem como a articulação destas açōes com a estrutura do sistema em seus diferentes níveis, de modo a preservar a sua integralidade e continuidade.

Historicamente, no Brasil, os primeiros cuidados de saúde dispensados aos grupos tribais partiram das missōes religiosas. Posțeriormente, com a criação do Serviço de Proteçáo ao Indio, na primeira década deste século, o atendimento médico aos grupos indígenas passou a ser atribuição desta agência governamental. A responsabilidade do Estado foi reafirmada no Estatuto do fndio que assegurou aos mesmos "o regime geral da Previdéncia Social"; "os meios de proteçấo à saúde facultados à comunhão nacional" e "especial assisténcia dos poderes páblicos em estabelecimentos a esse fim destinados" (Art. 54 e 55).

O SPI nâo tinha uma estrutura organizada e abrangente de assistência à saúde e atendia basicamente às situaçōes de surtos epidémicos advindos da perda do isolamento. Ainda em sua época surgiu a experiência pioneira de Noel Nutels, atraves do Serviço de Unidades Sanitárias Aero-Transportadas, ligado ao Ministério da Saúde. Este, embora se propondo inicialmente apenas a controlar a tuberculose em áreas indigenas, na prática ampliou o espectro das açōes de saúde desenvolvidas (COSTA, 1986).

A primeira tentativa de sistematizaçāo do atendimento de saúde em áreas indígenas, foi a criação das equipes volantes de Saúde, no ámbito da Divisão de Saúde da FUNAI, sucedánea do SPI (COSTA, loc. cit.). Este esquema, que persiste, é o responsável pela maior parte das açóes de saúde hoje desenvolvidas em áreas indígenas. Este modelo, de pouca eficácia, esbarrou em várias dificuldades, dentre as quais a falta de planejamento e de integralidade das açôs; política de remuneração não contempladora de tempo integral; caréncia crónica de infra-estrutura e recursos; falta de articulação com outros níveis de atençáo; ausência de um sistema de informaçóes em saúde e o preparo inadequado de quadros para atuação em comunidades culturalmente distintas. A falta de uma estrutura adequada de atendimento à saúde na atual agência Federal de assuntos indígen as (FUNAI), com múltiplas atribuiçōes, resultou, de forma compensatória, em uma pletora de convênios com entidades governamentais e nãogovernamentais.

Devem ser citadas outras experiências assistenciais de ámbito mais localizado, envolvendo a participação de entidades religiosas; organizaçóes não-governamentais (CCPY, 1987), escolas médicas (BARUZZI 
et al, 1978) e projetos de desenvolvimento regional (VIEIRA FILHO, 1988).

\section{ESPECIFICIDADES DOS CUIDADOS DE SAÚDE A POPULAÇŌES INDfGENAS}

Pode-se distinguir algumas peculiaridades no que tange ao trabalho em saúde em comunidades tribais, destacando-se as seguintes:

a) Situação de Transculturação - dentro da questão mais ampla do processo aculturativo, observado com intensidade e rapidez variáveis ap6s o contato com a sociedade nảo india envolvente, a transculturação no campo da sáde surge pela introduçáo de um conjunto de princípios e práticas do sistema méticu oficial em comunidades que vém lidando com as questóes de saúde-doença através de sistemas tradicionais de crenças e práticas de cura. A sobreposição destas duas medicinas envolve conflitos de compatibilizaçăo e aceitação tanto por parte dos receptores como dos executores das açóes. Neste contexto, tem papel fundamental a intermediação antropológica no acompanhamento dos programas de saúde e, principalmente, na formaça de pessoal de saúde - índios e não índios - para atuaçâo em comunidades indígenas. $O$ instrumental conceitual da antropologia médica ao elucidar a concepçáo indígena do organismo humano, da causalidade das doenças e das terapéuticas da medicina tradicional, subsidia e possibilita o processo de integraçāo controlada entre os dois sistemas méticos.

b) Situação Geográfica - a maioria das comunidades indígenas brasileiras se localiza em regiōes distantes da Amazónia e Centro-Oeste, com aldeias mais ou menos esparsas e de baixa densidade demografica. Isto implica dificuldades de acesso que, aliadas a deficiéncia da infra-estrutura local e recursos, contribuem para a descontinuidade na execu gấo das açós e programas. Neste contexto, toma-se imprescindível um sisteme de comunicaçós permanente com outros níveis de referencia. A elevacáo dos custos operacionais, principalmente em funçáo da dificuldade de manutençấo de equipamentos e instalaçð̋es, além da grande dependencia do transporte acreo 6 outro aspecto a ser considerado. Uma outra conseqūéncia 6 a dificuldade de permanéncia prolongada de equipe de satide não-índia nestas áreas em virtude do isolamento social - profissional e auséncia de comodidades das f́reas urbanas.

c) Dinâmica do Perfil Epidemiológico - é conhecido

Cadernos de Sadde Pablica, RJ, 5(4): 441-450, out/dez, 1989. 
o rápido ciclo de adaptação às enfermidades antes desconhecidas por grupos tribais isolados do contato com a sociedade näo indigena e que sofrem grandes transformaçōes aculturativas em seus hábitos e condiçōes de vida. De uma situação inicial de equilíbrio por convívio secular com processos in fecciosos de carater endêmico e baixa letalidade, iniciam-se surtos de viroses introduzidas, com alta morbidade e mortalidade e importantes repercussōes na organização social. Se superada esta fase, com a continuidade da reproduçāo biológica, inicia-se uma nova etapa na qual prevalecem os problemas dentários e os processos infecciosos da "aculturaçāo parcial" tais como infecções cutâneas, tuberculose, DST, diarréia, malária etc. Estes resultam principalmente da sedentalização forçada, do desequiIfbrio alimentar, padrāo inadequado de higiene individual e contato mais íntimo com as populaçóes urbanas. Por fim, a terceira etapa que completa a "transição epidemiológica" (YOUNG, 1988 b) ocorre com a maior integração à sociedade envolvente $e$ as perdas e aquisiçōes culturais decorrentes, caracterizando-se pelo aumento das doenças crônico-degenerativas (câncer, hipertensão, diabetes etc.) com o surgimento de um perfil de morbi-mortalidade mais próximo ao da sociedade nāo-índia. Tal se deve basicamente ao estresse social, à aculturação alimentar radical e à exposição a poluentes ambientais e produtos industrializados. É também característico desta fase o surgimento de um maior índice de doenças mentais (alcoolismo, suicídio) resultantes da desintegração social e marginalidade econômica, que explicam a participação dos acidentes e violências como as mais importantes causas de mortalidade em grupos largamente aculturados (YOUNG, 1983; RHOADES et al, 1987 b).

A constatação destas rápidas mudanças nos perfis de morbi-mortalidade que se seguiram aos processos de transformação socio-cultural, bem como a expectativa de continuidade deste processo, colocam os planejadores e administradores de serviços de saúde em situaçäo de poderem se preparar para reduzir o impacto destes fenómenos nos niveis de saúde da comunidade.

\section{ALGUMAS PROPOSTAS}

Conforme citado na Conferência de Proteçāo à Saúde do Indio, o relatório final apontou diretrizes relativas à questão da organizaçāo, pelo poder público, dos serviços de saúde para as comunidades etnicamente diferenciadas. Dentre elas destacam-se a participaçáo de representantes indígenas na formulação de políticas - execução das açōes e serviços; a criação de uma agéncia específica para assuntos de saúde indígena 
no âmbito do ministério responsável pela coordenação do SUS e o desenvolvimento de estratégias de atenção primaria a nível local que respeitem as especificidades etnoculturais. Retomaremos algumas destas proposiçōes, consideradas como ponto de partida para a discussăo da integração da assistência aos indígenas às redes de serviços do Sistema Único de Saúde.

É importante enfatizar que a saúde dos grupos tribais é expressão direta das formas tradicionais de ocupação do espaço territorial que assegurem a reprodução biológica e cultural dos grupos; da integridade de seus sistemas de crenças e valores responsáveis pela coesão social, bem como das relaçōes de contato com a sociedade branca envolvente e, portanto, da política indigenista desenvolvida no país.

Algumas estratégias a serem consideradas são as seguintes:

a) Distritalização diferenciada - dar-se-ia através da criação de áreas especiais de saúde (Distritos Sanitários) que englobem apenas comunidades indígenas, segundo critérios geográficos, demográficos e culturais a serem especificados. O que confere um carater especial a estas áreas, além das barreiras lingüísticas, é a necessidade de se organizarem os sistemas locais de saúde de modo a permitir:

1) a manutenção complementar das práticas tradicionais de cura.

2) o treinamento especial dos profissionais de saúde não-indios com base em conhecimentos etnológicos.

3) o estabelecimento de formas diferenciadas de articulação com as diferentes instâncias de gestão do SUS. Em relação a este último aspecto, a integração destas áreas com o sistema não se daria necessariamente através do nível municipal, podendo se dar a nível estadual ou mesmo central, dependendo do grau de aculturaçāo e integração na sociedade envolvente e do perfil mórbido. Esta flexibilidade na forma de articulação dos distritos sanitários indígenas no SUS é fundamental pois sâo bem distintas as necessidades e capacidades de comunidades autóctones pouco contatadas e isoladas na floresta amazônica em relaçāo às de outras com séculos de contato e que se localizam próximo a centros urtanos, como se observa no Brasil.

É questionável se a simples municipalização da assis tência à saúde dos grupos indígenas trará benefícios reais a estas comunidades. Estas, em geral, são precariamente toleradas ou mesmo rechaçadas pela população regional, e pode-se prever a incapacidade do Poder Municipal em reconhecer a situação cultural especial dos grupos tribais bem como de preparar adequadamente quadros para o atendimento, em função de conflitos decorrentes da não-assimilaçāo étnica, de preconceitos e de disputas fundiárias. neste sentido, Cadernos de Saúde Pública, RJ, 5(4): 441-450, out/dez, 1989. 
a distritalização diferenciada surge como alternativa para garantir o acesso real dos índios aos serviços e a equidade no atendimento, pressupostos para um Sistema de Saúde socialmente justo.

Por outro lado, o fortalecimento destes sistemas locais, através do treinamento, nas próprias comunidades, de alguns dos membros como agentes de saúde capacitados para desenvolver cuidados básicos e educação para a saúde, garantiria maior autonomia e continuidade das açōes de saúde neles desenvolvidas bem como a reduçăo dos custos operacionais. Esta foi a estratégia desenvolvida para ampliação efetiva da cobertura dos serviços para as áreas indígenas em países que hoje têm um sistema estruturado atendendo estas populaçōes de difícil acesso, como os EUA (BATHKE, 1974; JUSTICE, 1978) e o Canadá (YOUNG, 1988). b) Participação Comunitária - sendo uma das premissas básicas para o melhor controle e planejamento dos serviços toma-se especialmente importante para os Distritos Sanitários Indígenas na medida em que os membros da comunidade conduzem o processo de integraçāo das práticas da medicina oficial aos valores culturais do grupo, o que reforçaria a sua auto-estima e autodeterminação.

Esta participação comunitária dar-se-ia através dos Conselhos Distritais de Saúde, onde haveria também a participação dos representantes locais do SUS, e de outras instituiçōes presentes como prestadoras de serviços, permitindo assim a adequada determinação de prioridades e estratégias assistenciais. Esta forma de participação seria o passo inicial para o desenvolvimento da autogestăo em saúde, conforme já se observa em algumas comunidades indígenas do hemisfério norte (MOFFATT, 1987; GARRO et al, 1986; RHOADES et al, $1987 \mathrm{a})$.

A transferência do controle dos programas de saúde para as próprias comunidades indígenas foi estabelecida como política tanto no Canadá em 1981, através do documerito ministerial "Transfer of Health Services to Indian Communities" (GARRO et al, loc. cit.), como nos EUA, ao reafirmar, por ocasiāo da criação do "Indian Health Service", como uma de suas metas o "encorajar a máxima participação dos indígenas no planejamento e administraçāo dos serviços do IHS e assisti-los no desenvolvimento de sua capacidade de integrar e gerenciar programas de saúde" (RHOADES et al, 1987a). Desde o início desta década grupos no Canadá com o apoio do Departamento de Saúde Canadense e de Universidades foram paulatinamente adquirindo o controle dos serviços de saúde e, a despeito de dificuldades iniciais relativas ao recrutamento de profissionais de saúde e o gerenciamento de fundos insuficientes, o esquema consolidou-se. 
Seria ainda fundamental a criação de Comissōes de Saúde Indigena, funcionando associadas aos Conselhos Estaduais de Saúde. Tais comissóes seriam compostas por representantes das naçöes indígenas e por profissionais de saúde pertencentes às estrut. 'ras de atendimento já existentes os quais passariam a ..tegrar - SUS. As principais atribuiçōes destas comissōes seriam supervisionar as referencias para atendimento a nível secundário e terciário; promover o estabelecimento dos Conselhos locais e ampara-los tecnicamente; planejar e avaliar programas de saúde; treinar equipes, alem da responsabilidade fiscal.

c) Agéncia de Saúde Indígena no Ministério Gestor do SUS - desde o 2: Congresso Indigenista Interamericano (1949) foi aprovada uma resolução defendendo a criação, nos Ministérios da Saúde dos Países Latinoamericanos, de uma seçāo de "Defesa Biológica dos Indígenas" com a finalidade de "estudar as doenças dos índios; preparar a bioestatistica e formar en fermeiros índios" (MARROQUIN, 1977).

Da mesma forma, a OMS, ao estabelecer o papel dos Ministérios da Saúde na Atenção Primária, discutindo as infra-estruturas de Sistemas de Saúde, referese no concernente às populaçōes especiais, à organização de serviços de saúde específicos em países com populaçōes aborígenes claramente identificadas (WHO, 1988).

Óbserva-se que os paises da América que hoje têm os methores indicadores de saúde para populaçōes indígenas inicialmente administraram os serviços de saúde para grupos autóctones através do órgāo governamental de assuntos indígenas, de amplaís atribuiçōes em diversas áreas, e ligados aos respectivos Ministérios do Interior, como nos EUA ("Bureau of Indian Affairs") e Canadá ("Department of Indian Affairs") (STONE, 1935; RHOADES et al, 1987a). Com a evolução dos Sistemas de Saúde respectivos, embora tenham tomado rumos distintos quanto ao papel do Estado na prestaçāo direta de Serviços e no financiamento do setor, foram criados serviços específicos de atençāo à saúde dos indígenas nos respectivos Departamentos de Saúde, em 1955, nos EUA (RHOADES et al, 1987a) e em 1945, no Canadá (YOUNG, 1984).

Por ocasião da Conferência de Proteção à Saúde do fndio a idéia foi levantada e hoje significaria a criação de uma Secretaria Técnica dentro da estrutura central de gestāo do SUS, com a finalidade de coordenação executiva das açōes de saúde indígena em todo o território. Teria assim a seu encargo: a normatização técnica, programação, orçamentaçāo, captação de recursos, articulação com o nível estadual, desenvolvimento específico de recursos humanos e processamento de informaçōes sobre saúde de grupos indígenas. E

Cadernos de Saúde Pública, RJ, 5(4): 441-450, out/dez, 1989. 
importante que esta unidade seja assessorada por representantes das entidades indigenistas, universidades, associaçōes de profissionais de saúde e outras instâncias governamentais reunidas em um Conselho.

O funcionamento desta agência junto ao nível central do SUS traria como vantagens um maior respaldo técnico e in tegração com outros setores govemamentais pertinentes, envolvidos em questōes de saúde.

E importante enfatizar que a diferenciação no atendimento à saúde dos grupos indígenas dentro do Sistema Único implica uma vinculaçẩo orçamentária específica para atendimento dos programas nas diferentes áreas.

\section{PERSPECTIVAS}

A reorganizaçāo do sistema de atençāo à saúde em âmbito nacional, para uma melhor integração e distribuição dos serviços em todo o território, se apresenta como a ocasião adequada para a construção de uma estrutura de saúde que atenda às necessidades cambiantes dos grupos indigenas brasileiros, que sofreram um processo de destribalização até então relativamente reduzido.

Da mesma forma, na necessária reestruturaçăo administrativa ministerial para a adequada gestāo do Sistema a nivel central, surge a oportunidade para a criação de um organismo específico para a coordenação executiva das ações de saúde e responsável pela elaboração e implementação de políticas de saúde para as populações indígenas. Estas embora se constituam em apenas $0,2 \%$ da população do país, apresentam, como um todo, um crescimento demográfico acima daquele observado na populaçāo não-índia, podendo-se prever um aumento rápido na demanda de atenção médicosanitária.Nos períodos de estabilidade demográfica que se seguiram às depopulações pós-epidêmicas iniciais, alguns grupos exibiram crescimento numérico acelerado, da ordem de $500 \%$ em duas décadas (RIBEIRO, 1982).

Deve ser lembrado que os esforços de reorganização in stitucional propostos, com o objetivo de melhorar 0 atendimento de saide para os índios, visam basicamente superar os aspectos biológicos adversos das fases iniciais da transição da morbi-mortalidade, pela proteção contra agravos de maior importância, notadamente os de natureza infecciosa. A etapa seguinte, mais difícil, e que não se resolve com a simples melhoria da qualidade e acesso aos serviços de promoção e recuperação da saúde, envolve uma verdadeira "profilaxia cultural" e implica assegurar-se a estas comunidades a possibilidade de direcionarem e controlarem o processo geral de aculturação e mudança em 
seus hábitos e estilos de vida tradicionais e a conseqüente participação progressiva na formação sócio-econômica dominante. Sem isto, encontraremos no futuro próximo o que já se observa nas comunidades aborigenes da Australia e países da América do Norte: perda de identidade cultural, da coesão social e da dignidade individual; baixos níveis de escolaridade e emprego; doenças mentais e violência em proporçōes epidêmicas.

Um papel importante na susten tação de programas e estruturas públicas de atendimento aos indígenas está reservado às instituiçōes universitárias e de pesquisa, bem como às entidades médicas e afins. As primeiras, promovendo a discussáo sobre aspectos relacionados à saúde de grupos tribais, bem como a participação efetiva em programas e pesquisas, contribuiriam para a produção de conhecimentos sobre a dinâmica do processo de saúde-doença nestas minorias étnicas bem como despertariam interesse e vocaçōes em profissionais de saúde em processos de formação. As entidades teriam importante contribuição a dar como, por exemplo, através da criação de comissōes técnicas permanentes de assessoramento a órgāos governamentais.

Urge que o setor público formulador de políticas setoriais de saúde incorpore de forma mais efetiva em suas discussōes sobre o futuro da assistência à saúde no Brasil a problemática específica das populaçōes indígenas que ainda mantêm, em grande medida, o seu conteúdo étnico original. Neste sentido, é funda: mental que as mesmas sejam consideradas como merecedoras de prioridades substantivas em termos de atendimento e que se aprofundem as questôes técnicas envolvidas na organização da assistência aos índios, com suas peculiaridades anteriormente citadas.

Findmente, deve-se ter em mente que não se pode forçar uma integração destes grupos ao sistema de saúde de forma nâo-diferenciada, já que eles sob os aspectos linguístico, ideológico e econômico se diferenciam da sociedade nacional como um todo.

\section{REFERÊNCIAS BIBLIOGRÁFICAS}

ANÔNMMO, 1988. Encontro Aponta Soluçöes para a proteção da Saúde do Indio, Saúde em Debate. (Ed. Espec.); Jan/88, pg. 60 .

BARUZZI, R. B. et ał 1978. Programa Médico Preventivo da Escoh Paulista de Medicina do Parque Nacional do Xingu. Rev. Antropol., Sáo Paub, 21 (2): 155-164.

B ATHKE, J., 1974. The Community Health Medic in Indian America, pp 69-74, In Who, Public Health Papers, n: 60, Geneva.

Cadernos de Saúde Pública, RJ, 5(4): 441-450, out/dez, 1989. 
CCPY, 1987. CCPY. Dez Anos de Trabalho. Comissão Criação Parque Yanomami, mimeogr., $80 \mathrm{pp}$.

COSTA, D. C., 1986. Política Indigenista e Assistência à Saúde. Noel Nutels e o Serviģo de Unidades San itárias Aéreas. Cad. Saúde Pública, 4 (3): 388-401.

GARRO, L. C.; ROULETTE, J. \& WHITMORE, R. G., 1987. Community Control of Health Care Delivery: The Sand Bay Experience. Can. J. Publ. Health, 77: 281-284.

JUSTICE, J. W., 1978. Adiestramiento a través de barreras culturales: la experiencia del Servicio de Salud Indio con el programa de adiestramiento de ayudantes de médicos en salud comunitaria: In: Modern Medicine and Medical Anthropology in the United States Mexico border population, Velimirovic, B. (ed.), pp 109-123, PAHO Sci. Publ. n: 359, Washington.

M ARR OQUIN, A. D., 1977. Balance del Indigenismo. Inst. Indigenista Inter americano, México, XXXI + 300pp.

MOFFAT, M. E. K., 1987. Land settlements and health care: The Case of James Bay Cree. Can. J. Publ. Health, 78: 223-227.

RIBEIRO, D., 1982. Os Indios e a Civilizaçao. Vozes, Petrópolis.

RHOADES, E. R. et al. 1987a. The Organization of Health Services for Indian People. Publ. Health Rep., 102 (4): 352-356.

RHOADES, E. R. al. 1987b. The Indian Burden of Illness and Future Health Interventions. Publ. Health Rep., 102 (4): $361-368$.

STONE, E. L., 1935. Canadian Indian Medical Services. Can. Med. Assoc. J., 33: 82-85.

VIEIR A FILHO, J. P. B., 1988. Fathas Assistenciais à Saúde de Populaçöes Indígenas, Saúde em Debate (Ed. Espec.) $\mathrm{Jan} / 1988$, pg 50-51.

WHO, 1988. Strenghthening Ministries of Health for Primary Health Care. Tech. Rep. Ser., n: 766.

YOUNG, T. K., 1983. Mortality parterns of isolated Indians in north western Ontario. Publ. Health Rep., 98: 467-475.

1984. Indian Health Services in Canada: a sociohistorical perspective. Soc. Sci. med., 18: 257-264.

1988a. Health Care and Culture Change. XI + 177 pp. Univ. Toronto Press, Toronto.

1988b. Are Subartic Indians Undergoing the Epidemiologic Transition? Soc. Sci. Med, 26 (6): 659-671. 